
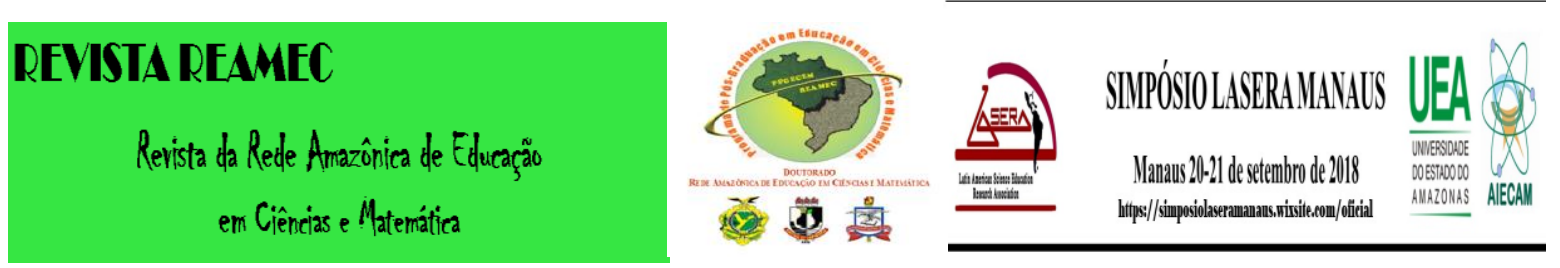

\title{
PERCEPÇÃO: ARTICULAÇÃO DAS PLANTAS MEDICINAIS AO ENSINO DE CIÊNCIAS
}

Gelciane da Silva Brandão ${ }^{a}$ José Vicente de Souza Aguiar ${ }^{\mathrm{b}}$ Naiara Batista de Vasconcelos ${ }^{\mathrm{c}}$

A R T I C L E I N F O

\author{
Palavras chave: \\ Percepção; \\ Plantas medicinais; \\ Ensino de Ciências. \\ E-mail: \\ ${ }^{a}$ brandaoanny@hotmail.com \\ b vicenteaguiar1401@gmail.com \\ ${ }^{\mathrm{c}}$ naiarabavasc@ hotmail.com;
}

\author{
R E S U M O
}

\section{INTRODUÇÃO}

Este artigo é um relato de experiência de uma prática perceptiva no Mercado Municipal Adolpho Lisboa ${ }^{1}$ na cidade de Manaus/AM, desenvolvido na disciplina "Tópicos Filosófico e Didático do Ensino de Ciências", do Programa de Pós-Graduação em Educação em Ciências da Universidade do Estado do Amazonas/UEA.

O objetivo foi executar um olhar perceptivo no interior do mercado, tendo como base o método fenomenológico. Para Merleau-Ponty (1999, p. 01) “[...]A fenomenologia é o estudo das essências, e todos os problemas, resumem-se em definir essências: a essência da percepção, a essência da consciência, por exemplo". Por meio do problema buscamos responder: é possível identificar no Mercado Municipal Adolpho Lisboa elemento com potencial para ser articulado ao Ensino de Ciências?

\footnotetext{
${ }^{1}$ O "Mercadão", como é conhecido o Mercado Municipal Adolpho Lisboa inaugurado em 1882, é um dos maiores patrimônios histórico-arquitetônico da cidade de Manaus, com elementos que refletem o período áureo da borracha (SILVA, 2015).

Revista REAMEC, Cuiabá - MT, V. 6, n. Especial, dez 2018, ISSN: 2318-6674

Revista do Programa de Doutorado da Rede Amazônica de Educação em Ciências e Matemática

http://periodicoscientificos.ufmt.br/ojs/index.php/reamec
} 


\section{REVISTA REAMEC}

Revista da Rede Amazônica de Edureação em Ciências e Matemática
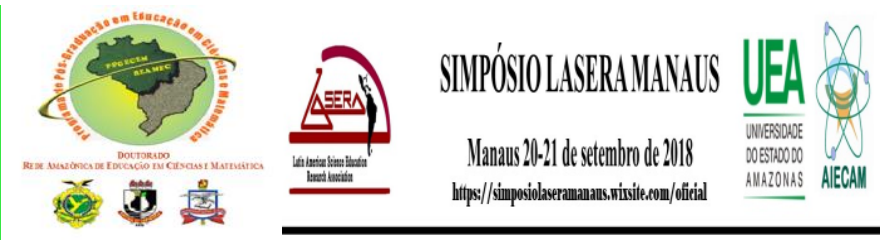

No primeiro momento de observação optamos por nos deslocar nos diversos ambientes do mercado, experenciando as sonoridades, os movimentos de quem entrava, saía ou permanecia dentro do mercado, os cheiros de frutas, verduras, pescado, as conversas informais do vendedor com o público que adentrava no local; todos esses detalhes foi destacado por meio da leitura do artigo científico do autor Oliveira (2000) "O trabalho do antropólogo: olhar, ouvir, escrever”, além da leitura da obra de Merleau-Ponty (1999)“Fenomenologia da Percepção”.

No mercado havia uma diversidade de elementos, mas nos chamou atenção o ambiente de venda de plantas medicinais. Através da observação e diálogo com o agente social percebemos que através deste tema, tínhamos como articular às discussões sobre Educação Ambiental no Ensino de Ciências com enfoque transversal.

Destacamos que essa atividade reúne sensações por meio do contato cognitivo (olhar e o ouvir) condições básicas para o Ensino de Ciências, podendo ser realizada por meio de uma prática de campo com alunos, proporcionando a realização de um deslocamento metodológico: olhar, ouvir e escrever, além da leitura de método para compreender a realidade (OLIVEIRA, 2000).

\section{METODOLOGIA}

O local da pesquisa foi o Mercado Municipal Adolpho Lisboa na cidade de Manaus/AM, que agrega para venda diversos produtos como por exemplo, peixes, carne, artesanato, frutas e verduras além de ervas medicinais.

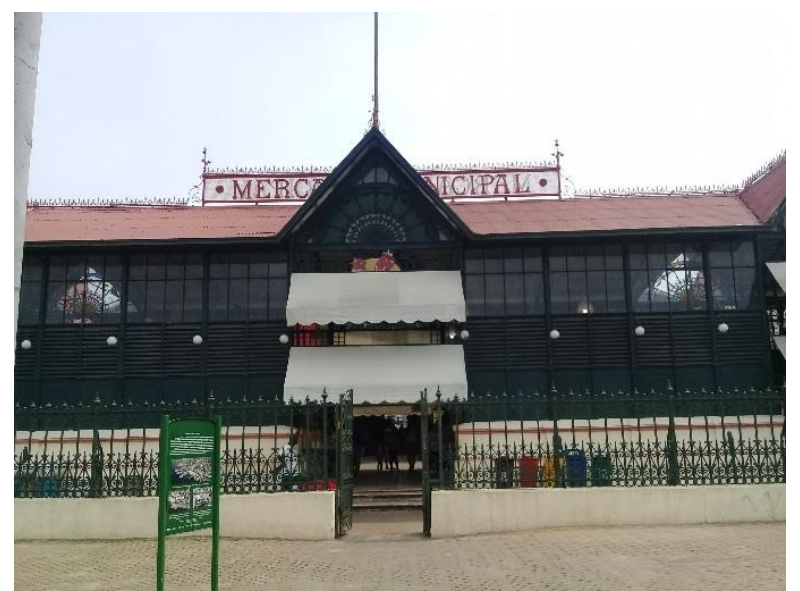

Figura 1 - Mercado Municipal Adolpho Lisboa

Revista REAMEC, Cuiabá - MT, V. 6, n. Especial, dez 2018, ISSN: 2318-6674

Revista do Programa de Doutorado da Rede Amazônica de Educação em Ciências e Matemática http://periodicoscientificos.ufmt.br/ojs/index.php/reamec 
Fonte: Brandão (2017)

"Situado no centro histórico de Manaus, com 3.500 metros quadrados de área construída, o conjunto arquitetônico do Mercado Adolpho Lisboa é composto por quatro pavilhões de ferro importados da Europa: o Central, o da Carne, o do Peixe e o das Tartarugas (GASPAR, 2012, p. 01).

O relato de experiência foi de natureza qualitativa, para Creswell (2010) sua relação de fundamenta em uma descrição profunda/densa dos acontecimentos, e é também “[..]uma forma de investigação interpretativa em que os pesquisadores fazem uma interpretação do que enxergam, ouvem ou entendem" (CRESWELL, 2010, 209).

O método de abordagem foi o fenomenológico que se dá a partir do que descreve Merleau-Ponty (1999, p. 01) “[...]É a tentativa de uma descrição direta de nossa experiência tal como ela é, e sem deferência à sua gênese psicológica e às explicações causais”.

A técnica usada foi o diálogo, precedida de uma análise descritiva a partir da experiência e da percepção de uma vendedora de plantas medicinais, pois “[...]O real deve ser descrito, não construído ou constituído. Isso quer dizer que não posso assimilar a percepção às sínteses que são da ordem do juízo, dos atos ou da predicação" (MERLEAU-PONTY, 1999, p. $05)$.

\section{CONSIDERAÇÕES SOBRE O ENSINO DE CIÊNCIAS}

A ciência é apresentada em diferentes abordagens, de acordo com o tempo em que ela foi construída, seja ela de: caráter Histórico (KUNH, 2017); com a sua Multiplicidade, (FEYRABEND, 1993); Complexidade (MORIN, 2003); holismo (CAPRA, 2006) e sua Dialética/histórico-crítica, MARX. Para Thomas Kuhn (2017) ela precisa ser pensada na perspectiva de paradigmas 2 relativos aos seus diversos campos de conhecimentos, cuja ciência corresponde aos momentos de realização sustentado pela aplicação do que denominou de resolução de quebra-cabeça. A ciência normal baseia-se em realizações científicas prévias reconhecidas por determinada comunidade científica. "[...] Essas realizações são reconhecidas durante algum tempo por alguma comunidade científica específica como proporcionando os fundamentos para sua prática posterior" (KUHN, 2017, p. 71).

${ }^{2}$ Estrutura e procedimento, algo que está mais consolidado.

Revista REAMEC, Cuiabá - MT, V. 6, n. Especial, dez 2018, ISSN: 2318-6674

Revista do Programa de Doutorado da Rede Amazônica de Educação em Ciências e Matemática

http://periodicoscientificos.ufmt.br/ojs/index.php/reamec 
Tratando do ensino de Ciências, há necessidade de se realizar um ensino baseado não só na concepção de Ciência como atividade humana, mas também social e historicamente construída. Para Kuhn (2017) a discussão sobre revolução científica é a própria ruptura com um determinado paradigma; é no sentido de compreendermos procedimentos de permanências e/ou rupturas de concepção de ensino que existe no ensino de Ciências que pretendemos através da fenomenologia realizar a pesquisa. E não de romper paradigmas, porque alcançar essa atitude, entendemos que é necessário tempo e estudos mais aprofundados.

O Ensino de Ciências na educação passa por discussões, cujos autores como Delizoicov; Angotti\& Pernambuco (2011) levantam o seguinte questionamento: Para quem ensinar Ciências? Torná-la universal e acessível a todos os níveis de ensino, não um privilégio de poucos, deveria ser o objetivo principal do ensino de Ciências, não somente uma reprodução de conhecimento.

Há uma postura no âmbito pedagógico que discute os temas concernentes à propagação de ciência no espaço escolar de maneira simplista, com destaque para a assimilação pelos estudantes de conteúdo do campo da ciência. O que pode estar relacionado a história da democratização da educação fundamental pública ocorrida há poucas somente na década de 1970, (DELIZOICOV; ANGOTTI \& PERNAMBUCO, 2011). Estes teóricos abordam a questão da Ciência para todos como um desafio a ser imposto, sem distinção de classes:

O desafio de pôr o saber científico ao alcance de um público escolar em escala sem precedentes - público representado, pela primeira vez em nossa história, por todos os segmentos sociais e com maioria expressiva oriunda das classes e culturas que até então não frequentaram a escola, salvo exceções - não pode ser enfrentado com as mesmas práticas docentes das décadas anteriores ou da escola de poucos e para poucos (DELIZOICOV; ANGOTTI \& PERNAMBUCO, 2011, p. 33).

Existem características distintas do público escolar, com valores, crenças, costumes e outras formas de ser e de viver, cujos saberes a priori dos estudantes não podem ser ignorados, pois cada um possui uma experiência de vida social e familiar diferente. Essa falta de representatividade no ensino de Ciências revela que há uma necessidade de mudança. Pois “[...]os diversos conhecimentos transmitidos e refutados no processo ensino-aprendizagem, concernente ao Ensino de Ciências, decorrem de pesquisas que, contínua e consequentemente, são ressignificadas a partir de processos investigativos...” (GONZAGA, 2013, p. 14).

Essa mudança não ocorre de forma rápida, ela é uma construção coletiva, que envolve à atuação do professor nos diferentes níveis de ensino, e, sobretudo uma preocupação quanto à Revista REAMEC, Cuiabá - MT, V. 6, n. Especial, dez 2018, ISSN: 2318-6674 Revista do Programa de Doutorado da Rede Amazônica de Educação em Ciências e Matemática http://periodicoscientificos.ufmt.br/ojs/index.php/reamec 
formação de professores de Ciências, que “[...] constituem lócus privilegiado para que essa disseminação se intensifique, à medida que, sistemática e criticamente, o novo conhecimento produzido pela área de ensino de Ciências passe a permear as ações docentes" (DELIZOICOV; ANGOTTI \& PERNAMBUCO, 2011, p. 41).

Para Gonzaga (2013) o cientificismo tem implicações no Ensino de Ciências e destaca que a história e a filosofia da ciência focam em um conhecimento prioritário: o científico. “[...]preocupa-se em dar a condição de verdadeiro e real ao conhecimento, é definitivo, é quantitativo, é laboratorial, é mecanicista; tem a preocupação de dar status distinto para a ciência, para o objeto de estudo e para os cientistas" (GONZAGA, 2013, p.17).

Mas quais as implicações desse cientificismo em pesquisas no âmbito do Ensino de Ciências? A primeira, é a consolidação do Ensino de Ciências que teve influência direta da filosofia e da história da Ciência. E desse modo, sente os efeitos dos “[...]avanços e retrocessos decorrentes dos resultados de investigações, que procuram legitimá-lo como área de conhecimento..." (GONZAGA, 2013, p.18).

Contudo pensamos que o Ensino de Ciências não pode ser tratado de forma onisciente, este deve proporcionar possibilidades de acesso e construção e descoberta constante de conhecimento. "Ensinar Ciências, implica em mudanças de postura, em possibilidades de tomadas de atitude capazes de levar os estudantes a compreenderem que o mundo que estudam não somente faz parte, mas também depende deles...” (GONZAGA, 2013, p. 108).

\section{BREVE HISTÓRICO: "PLANTAS MEDICINAIS"}

O histórico de reconhecimento das plantas medicinais pela Organização Mundial de Saúde (OMS) data do ano de 1978, que apresenta recomendações em nível mundial do uso racional das plantas medicinais, assim como dos fitoterápicos na atenção à saúde da população (AMARAL et al, 2005).

Em atendimento as recomendações da OMS o Brasil criou a Política Nacional de Plantas Medicinais e Fitoterápicos, por meio do Decreto $n^{\circ} 5.813$, de 22 de junho de 2006 (BRASIL, 2006).

Em 2008 foi criado o Programa Nacional de Plantas Medicinais e Fitoterápicos, tendo como objetivo central as ações de "acesso seguro e uso racional da população as plantas 


\section{REVISTA REAMEC}

Revista da Rede Amazônica de Edureação em Ciências e Matemática
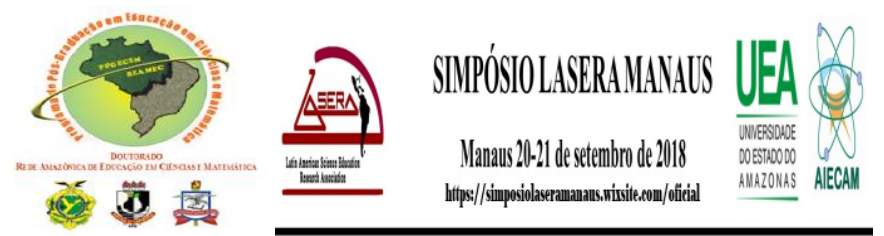

medicinais e fitoterápicos, o uso sustentável da biodiversidade brasileira e a valorização e preservação do conhecimento tradicional das comunidades e povos" (BRASIL, 2008).

Destaca-se que existem 66 espécies de plantas medicinais que são aprovadas através da Resolução RDC N 10, de 09 de março de 2010, pela Agência Nacional de Vigilância Sanitária-ANVISA, com publicação reconhecida no Diário Oficial da União (BRASIL, 2010) e do qual a população pode fazer uso para tratamento de doenças, isso demonstra o potencial que podemos encontrar na biodiversidade e da urgência de discutir o tema em diferentes áreas de ensino.

No Mercado Municipal Adolpho Lisboa encontramos uma variedade de espécies de plantas medicinais, que são comercializadas livremente na área externa, tanto na forma natural (as plantas naturais) ou processadas.

\section{A PERCEPÇÃO DAS PLANTAS MEDICINAIS NO MERCADO ADOLPHO LISBOA EM MANAUS/AM}

Durante a visita no Mercado Municipal Adolpho Lisboa, observamos a venda de plantas medicinais em forma natural, sementes, cascas e também processada em um dos ambientes do mercado.

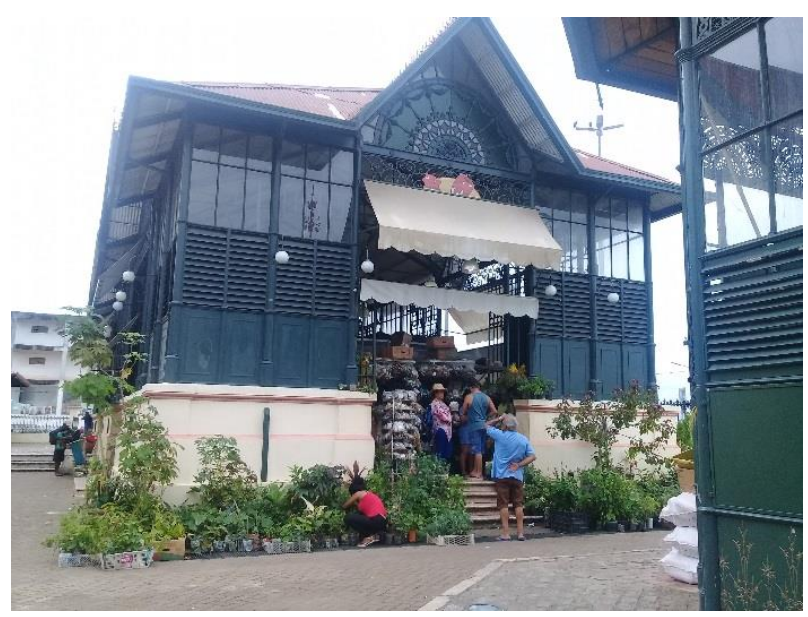

Figura 2 - Local de venda das ervas medicinais Fonte: Brandão (2017)

Segundo a Vendedora (1) há pessoas que preferem comprar a planta e cultivar em casa. "Vendemos das duas maneiras, as plantas vivas e secas para consumo em forma de chá. Percebemos que as pessoas ainda preferem comprar em forma de plantas, porque acham que dessa forma o efeito para medicação é mais rápido. Eu que trabalho a muitos anos acho que é 


\section{REVISTA REAMEC}

Revista da Rede Amazônica de Eduração em Ciências e Matemática
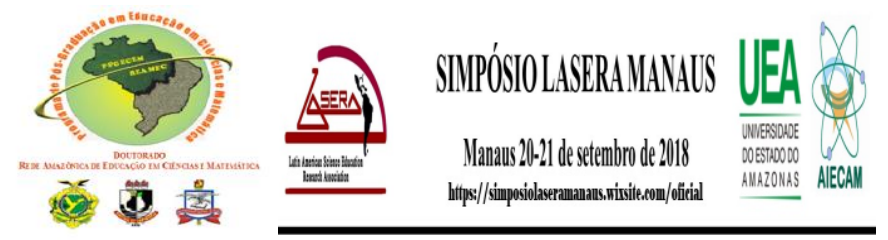

só uma questão de dosagem, as duas formas têm efeitos", (RELATO DA VENDEDORA 1, 2017).

A vendedora (1) não sou soube mensurar quantos tipos de plantas existem para venda no local, mas destacou algumas que são comercializadas e para qual tratamento são indicadas.

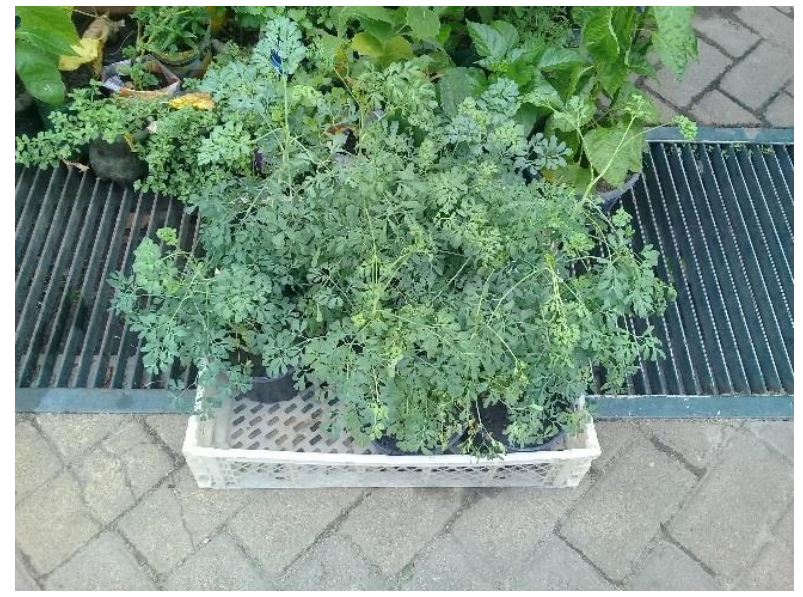

Figura 3 - Arruda(Rutagraveolens)

Fonte: Brandão (2017)

A planta de arruda (Rutagraveolens) possuem propriedade analgésica, béquica, emoliente e anti-helmíntica (LAMEIRA, 2008). "Há uma crendice de que a folha de arruda serve também para mau olhado, colocar uma folha na bolsa, ou em casa pode ajudar contra energias negativas. É uma planta que vendemos muito" (RELATO DA VENDEDORA 1, 2017).

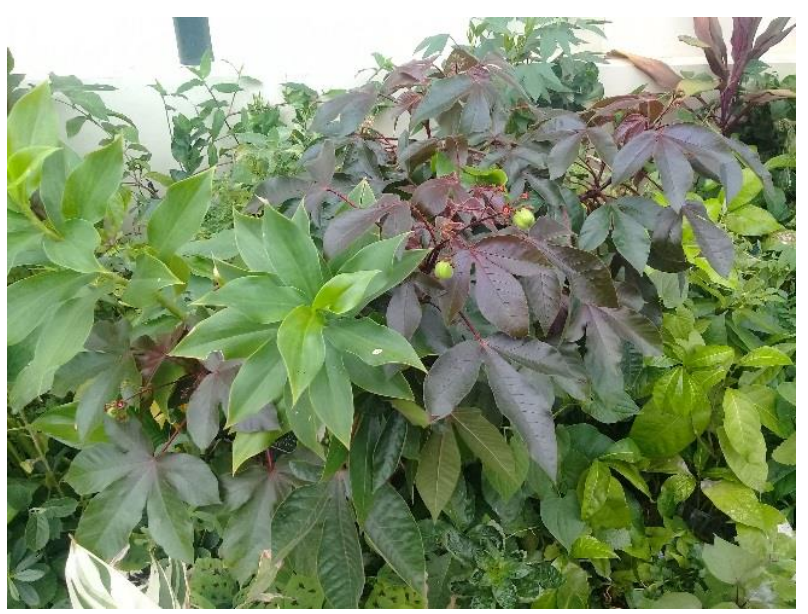

Figura 4 - Pião roxoJatrophagossypifolia L)

Fonte: Brandão (2017) 


\section{REVISTA REAMEC}

Revista da Rede Amazônica de Eduração em Ciências e Matemática
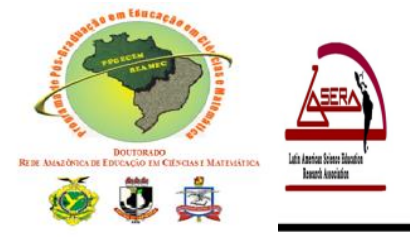

SIMPOSSIOLASERAMANALIS

Manaus:20-21 de setembro de 2018

hithss//simposiolaserenmanans, wisisiteroum/oticial

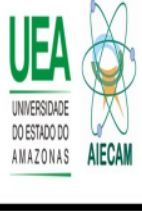

O pião roxo (Jatrophagossypifolia $L$ ) recomendado para inflamação na garganta e útero, ingerindo o chá das folhas (OLIVEIRA, 2007). "Acredita-se que o banho feito desta planta é bom para dar banho em crianças que são muito bravas, ajuda a tranquilizar" (RELATO DA VENDEDORA 1, 2017). O comentário da vendedora destaca uma crença e que tem pessoas que acreditam, repassando o conhecimento para outras gerações.

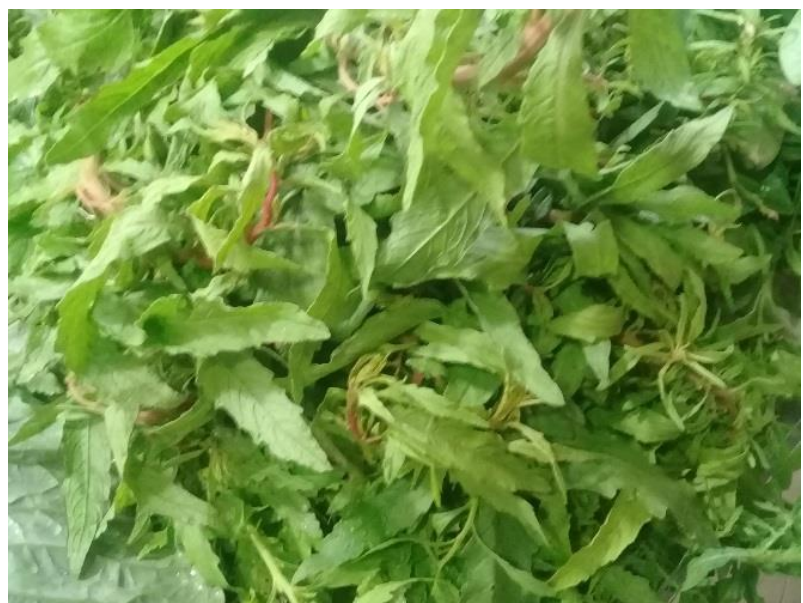

Figura 5 - MastruzChenopodiumambrosioides L) Fonte: Brandão (2017)

O mastruz (Chenopodiumambrosioides L.) contém propriedades vermífuga e expectorante, preparado do insumo da folha (LAMEIRA, 2008). "Essa planta é muito boa para machucados, ajuda na cicatrização de feridas, boa para tosse" (RELATO DA VENDEDORA 1, 2017).

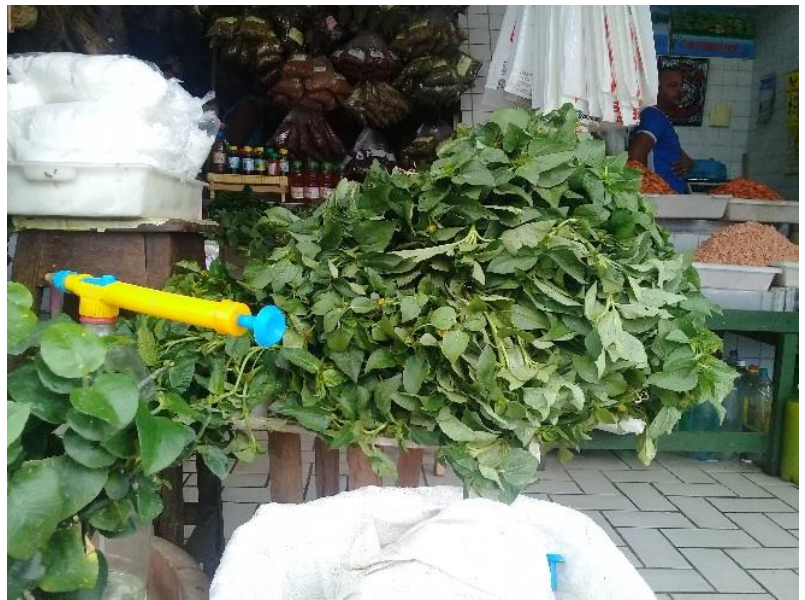

Figura 6 - Folhas de jambú(SpilanthesoleraceaJac)

Fonte: Brandão (2017) 


\section{REVISTA REAMEC}

Revista ta Rede Amazonitica de Eduraçăo

em Ciêneias e Matemática
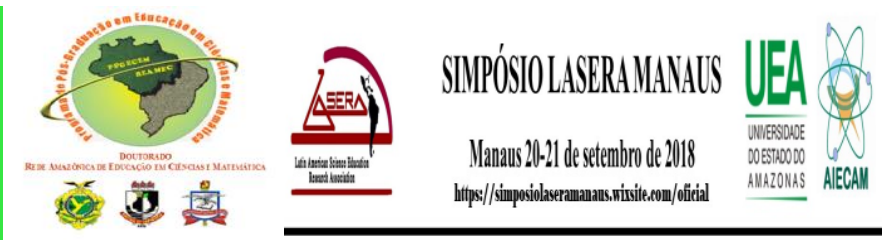

O jambú (SpilanthesoleraceaJac.), a forma de uso é para hemorragia, ingerindo o chá proveniente da folha ou da raiz (LAMEIRA, 2008). "O jambú é muito usado na culinária junto com o tucupí e também de uma iguaria da nossa região que é o tacacá" (RELATO DA VENDEDORA 1, 2017).

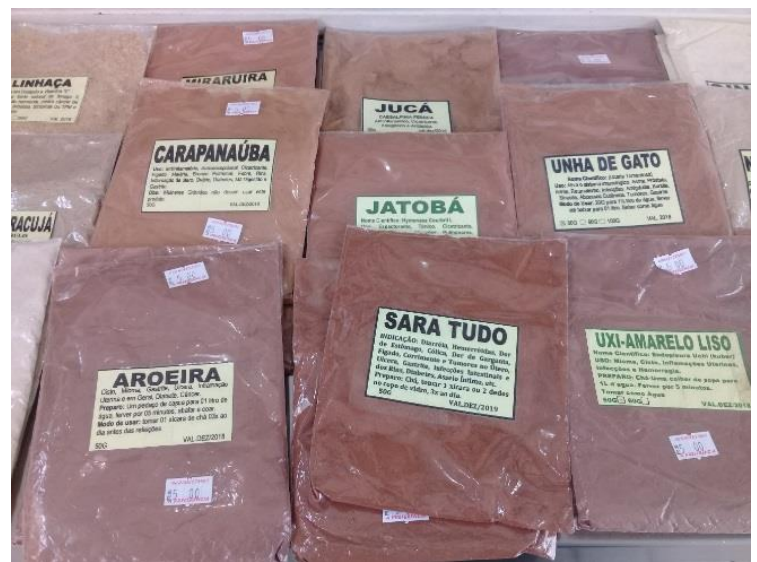

Figura 7 - Plantas medicinais processadas Fonte: Brandão (2017)

No mercado é comercializado ainda plantas medicinais em pó para o preparo de chá. O processo de secagem e transformação da planta passa por um processo que inicia com a secagem. A venda da planta processada é bem consumida, "primeiro porque basta ferver a água e colocar a quantidade recomendada para o chá. Geralmente as pessoas não sabem manipular as ervas em forma de planta para o consumo, assim elas acham mais fácil” (RELATO DA VENDEDORA 1, 2017).

$\mathrm{Na}$ banca da vendedora observamos diversas plantas em forma de pó a exemplo daCarapanaúba(Aspidospermanitidum.); que“[...]é uma árvore de tronco sulcado e retilíneo, com até $25 \mathrm{~m}$ de altura e diâmetro de 40 a $60 \mathrm{~cm}$ e com muitas" (BEZERRA, 2015, p. 02). Suas propriedades medicinais envolvem inflamações do útero e ovário, indicada para tratamento de diabetes, câncer e doenças no estômago (RIBEIRO et al, 1999), há registro de sua eficácia como método anticoncepcional, febre e doenças reumáticas (PEREIRA et al, 2006).

O Uxi-Amarelo (Endopleurauchi (Huber) Cuatrec.)"espécie pertencente à família Humiriaceae, é uma espécie originária da Amazônia brasileira, encontrada em floresta de terra firme. Popularmente, é conhecida comoUxi-amarelo" (BEZERRA, 2015, p. 03). Sua utilização é feita para tratar artrite, colesterol, diabete e ainda como anti-inflamatório (CORRÊA, 1984). 
E o Jucá (Caesalpineaferrea), que conforme informações contidas na capa da embalagem, possui propriedades anti-inflamatórias. Segundo Angely (1969) a espécie de Jucá (Caesalpiniaferrea) foi catalogada pela primeira vez no ano de 1828. A árvore dessa espécie atinge um tamanho grande, e a característica de seu tronco é de aspecto liso com manchas brancas, suas flores amarelas, desenvolvem cachos. É uma espécie originária do Brasil (CRUZ, 1965).

A procura pelas plantas medicinais é constante, “todos os dias as pessoas procuram para o tratamento de algum tipo de doença, isso é comum no nosso dia a dia. Pela nossa experiência a gente orienta como usar a favor da saúde" (RELATO DA VENDEDORA 1, 2017). São conhecimentos adquiridos por meio da experiência de uma geração a outra, para Almeida (2008) os conhecimentos tradicionais englobam além das plantas medicinais, e geram discussões que envolvem economicamente grandes empresas de cosméticos e laboratórios de biotecnologia.

Foi possível perceber que as plantas medicinais são comercializadas de diferentes formas, gerando renda e troca de experiências para quem vende e também paraquem compra.Economicamente é uma atividade rentável, no Ensino de Ciências alguns temas poderiam ser articulados a Educação Ambiental, discutindo com o aluno além daquilo que os sentidos podem perceber, lembrando que"[...] percebido comporta lacunas que não são simples imperfeições" (MERLEAU-PONTY, 1999, p. 33).

Ressaltamos que através dessa experiência foi possível perceber que há possibilidade de articularmos dentro do mercado determinados temas como o Ensino de Ciências; o olhar fenomenológico no possibilita perceber além das aparências e explorar os temas. "A fenomenologia está completamente envolvida com retornar, redespertar e redescobrir, e, assim, a questão de abertura de Merleau-Ponty pode ser lida como uma aplicação reflexiva sobre esse envolvimento" (CERBOBE, 2014, p. 159).

\section{ROTEIRO DE INTERVENÇÃO PARA O ENSINO DE CIÊNCIAS TEDO COMO BASE A FENOMENOLOGIA DE MERLEU-PONTY (1999)}

A experiência de observação no mercado Municipal Adolpho Lisboa, nos possibilitou pensar que é possível realizar uma atividade para o Ensino de Ciências a partir das plantas 


\section{REVISTA REAMEC}

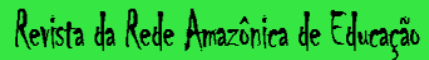

em Ciêneias e Matemática
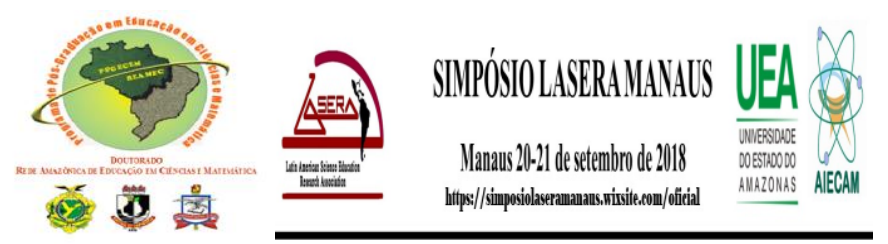

medicinais. A proposta inicial pode ser baseada para seu desenvolvimento no ensino fundamental a partir da fenomenologia da percepção.

O roteiro, baseado na leitura na obra Fenomenologia da percepção elege três categorias a serem aplicadas nesta atividade prática:

Primeiro por meio da Sensação: estimular a sensibilidade dos alunos quanto ao reconhecimento das plantas medicinais através do cheiro a fim de realizar uma experiência vivida, observar as reações ao sentir e tocar as plantas e trazer essas reações para a discussão no campo fenomênico. É uma maneira de estimular o diálogo em sala de aula, de fazer com que os alunos percebam além da aparência, já que para Merleau-Ponty $(1999$, p. 28) “[...]o sensível é o que aprendemos com os sentidos".

Segundo, através do Ver: realizar um estudo prévio da percepção dos alunos sobre plantas medicinais ainda na sala de aula - antes da visita ao mercado ou outro espaço nãoformal que reúna esse tema escolhido. Essa é uma forma de estimular o aluno a pensar se ele sabe do que se trata o tema, é um momento de levantar hipóteses para a prática de campo, pois “[...]o visível se é o que se aprende com os olhos” (MERLEAU-PONTY, 1999, p. 28).

E terceiro o Ouvir: realizar atividade de intervenção com os alunos sobre plantas medicinais, a fim de estimular a percepção sobre as plantas medicinais, uma vez que "[...]O próprio cientista deve aprender a criticar a ideia de um mundo exterior em si" (MERLEAUPONTY, 1999, p. 32). Nesta atividade o aluno terá contato com as plantas medicinais, esta atividade pode ser realizada no mercado, em feira, quintal urbano, horta escolar, ou qualquer outro espaço não-formal que possibilite esta intervenção.

E por fim, observar se após o trabalho realizado com os alunos quais as impressões sobrea experiência vivida, instigando a debaterem o tema a partir de uma concepção mais abrangente de ensino, possibilitando se posicionar de maneira crítica. "Pensamos saber o que é sentir, ver, ouvir, e essas palavras agora representam problemas. Somos convidados a retornar às próprias experiências que elas designam para defini-las novamente" (MERLEAU-PONTY, 1999, p. 32).

\section{DISCUSSÃO DOS RESULTADOS: POSSIBILIDADE DE ARTICULAÇÃO AO ENSINO DE CIÊNCIAS}

Revista REAMEC, Cuiabá - MT, V. 6, n. Especial, dez 2018, ISSN: 2318-6674

Revista do Programa de Doutorado da Rede Amazônica de Educação em Ciências e Matemática

http://periodicoscientificos.ufmt.br/ojs/index.php/reamec 
Perceber a ciência nos promove também, e colabora para conter e prognosticar as mudanças que acontecem no meio ambiente, e podemos obter visões diferentes de acordo com o momento em que os fenômenos acontecem, nesse sentido observamos que o tema referente as plantas medicinais podem ser articulados às discussões sobre Educação Ambiental, tema que precisa ser discutido frequentemente em sala de aula em diferentes enfoques.

Para dirigir uma prática coesa, os Parâmetros Curriculares Nacionais destacam que o tema sobre Meio Ambiente seja desenvolvido como um tema transversal,envolvendo não só as áreas do ensino: Língua Portuguesa, Matemática, Ciências Naturais, História, Geografia, Arte, Física e Língua Estrangeira. Mas devemos legitimar os eixos: Ética, Saúde, Meio Ambiente, Orientação Sexual e Pluralidade Cultural.

Observado o potencial do tema "Plantas medicinais"podemos interliga-lo no âmbito da Educação Ambiental sobre a redução da diversidade biológica afim de levantar questionamentos sobre a importância da preservação das espécies para garantir qualidade de vida às presentes e futuras gerações. As plantas medicinais estão neste campo de discussão, uma vez que, se o meio ambiente não for preservado fica impossível descobrir por exemplo propriedades medicinais que servirão para a cura de doenças.

O conceito de educação ambiental definido pela comissão interministerial na preparação da ECO-92 englobou outras dimensões, conforme destacam Leão e Silva (1995, p. 28:

A educação ambiental se caracteriza por incorporar as dimensões socioeconômica, política, cultural e histórica, não podendo se basear em pautas rígidas e de aplicação universal, devendo considerar as condições e estágios de cada país, região e comunidade, sob uma perspectiva histórica. Assim sendo, a Educação Ambiental deve permitir a compreensão da natureza complexa do meio ambiente e interpretar a interdependência entre os diversos elementos que conformam o ambiente, com vistas a utilizar racionalmente os recursos do meio na satisfação material e espiritual da sociedade, no presente e no futuro.

A Lei no 9.795/99 dispôs sobre a Educação Ambiental e instituiu a Política Nacional de Educação Ambiental, em seu artigo $1^{\circ}$ aponta o entendimento da educação ambiental como:

[...]os processos por meio dos quais o indivíduo e a coletividade constroem valores sociais, conhecimentos, habilidades, atitudes e competências voltadas 
para a conservação do meio ambiente, bem de uso comum do povo, essencial

à sadia qualidade de vida e sua sustentabilidade (BRASIL, 1999, p. 02).

É importante registrar que o artigo $1^{\circ}$ descreve o Meio Ambiente como uso de bem comum do povo em consonância com o disposto na Constituição Federal (1988) e como base nas condições de reprodução da vida de forma saudável. Já o artigo $2^{\circ}$ impõe ser a Educação Ambiental "um componente essencial e permanente da educação nacional, devendo estar presente, de forma articulada, em todos os níveis e modalidades do processo educativo, em caráter formal e não-formal” (BRASIL, 2013, p. 02).

Por fim, o artigo $3^{\circ}$ da Política Nacional de Educação Ambiental, Lei no 9.795/99, descreve as atribuições de cada setor da sociedade e desta como um todo na condução dos processos educativos voltados ao meio ambiente, definindo, no capítulo II destaca que é dever das instituições educativas "promover a educação ambiental de maneira integrada aos programas educacionais que desenvolvem" (BRASIL, 1999, p. 03).

\section{CONCLUSÃo}

O relato de experiência foi desenvolvido no Mercado Municipal Adolpho Lisboa em Manaus/AM. No ensino de ciências é fundamental superar o obstáculo da experiência primeira, aquela onde o aluno não enxerga possiblidades de aprendizagem e articulação ao ensino promovendo uma ruptura, "e não continuidade, entre a observação e a experimentação" (BACHELARD, 1996, p. 25).

A experiência nos proporcionou perceber que há possibilidade de mediar diferentes ambientes na prática de ensino, o mercado pode ser um importante aliado para transcender o espaço escolar em articulação aos espaços não-formais. Por meio das plantas medicinais podemos discutir a Educação Ambiental de maneira transversal, possibilitando com que o aluno possa refletir sobre o ambiente que vive.

Contudo, reconhecemos que os processo dialógico do sabere da ciência formal é importante para a vida escolar, mas a proposta busca demonstrar uma outra possibilidade de articulação além dos livros tradicionalmente incorporados no processo de ensino. $\mathrm{Na}$ 
realidade, perceber o potencial existente nos espaços não-formais é um desafio tanto para educadores quanto para o próprio sistema de ensino.

\section{REFERÊNCIAS}

ALMEIDA, Alfredo Wagner Berno de. Conhecimento tradicional e biodiversidade: normas vigentes e propostas. Manaus: PPGAS-UFAM/NSCA-CESTU-UEA Edições, 2008.

AMARAL, A. C. F.; SIMÕES, E. V.; FERREIRA, J. L. P. Coletânea Científica de Plantas de Uso Medicinal. Rio de Janeiro: Fiocruz, 2005.

ANGELY, J. Flora Analítica e Fitogeográfica do Estado de São Paulo. São Paulo: Ed. Phyton, 1969.

BACHELARD, Gaston. A formação do espírito científico: contribuições para uma psicanálise do conhecimento. [tradução Esteia dos Santos Abreu]. Rio de Janeiro: Contraponto, 1996.

BEZERRA, StiffannyAlexa Saraiva; MARI, Maikel Lamego Guimarães; AZEVEDO, Adriana Siqueira; MOREIRA, Rosiane Martins; CAMPOS, Suelen de Souza; OLIVEIRA, Bruna Rocha de.; SANTOS, Roberta Monique da Silva; MONTEIRO, Newton Coelho. Cadeia produtiva de duas espécies florestais de uso farmacológico: carapanaúba (aspidosperma spp.) E uxíamarelo (Endopleurauchi (Huber) Cuatrec.) Manaus: UFAM, Departamento de Engenharia Florestal - Instituto Nacional de Pesquisas da Amazônia, CPBO, 2015.

BRASIL. Agência Nacional de Vigilância Sanitária/Ministério da Saúde. Diário Oficial da União. Resolução - RDC $\mathbf{N}^{\mathbf{0}}$ 10, de 09 de março de 2010. Disponível em: <http://www.fitoterapia.com.br/portal/pdf/rdc10.pdf> Acesso em 10/out./2017.

BRASIL. Constituição da República Federativa do Brasil. Brasília, DF: Senado Federal: Centro Gráfico, 2013.

BRASIL. Lei 9.795/99. Política Nacional de Educação Ambiental. Disponível em: <http://www.planalto.gov.br/ccivil_03/leis/19795.htm>Acesso em 15 de julho 2018.

BRASIL. Política Nacional de Plantas Medicinais e Fitoterápicos. Decreto $\mathbf{n}^{\mathbf{0}} \mathbf{5 . 8 1 3}$, de 22 de junho de 2006. Disponível em: 〈http://189.28.128.100/dab/docs/legislacao/decreto5813_22_06_06.pdf $>$ Acesso em 19 de jul. de 2018. 
BRASIL. Programa Nacional de Plantas Medicinais. Disponível em: <http://bvsms.saude.gov.br/bvs/publicacoes/programa_nacional_plantas_medicinais_fitoterap icos.pdf $>$ Acesso em 20 de jul. de 2018.

CAPRA, F. Alfabetização ecológica: a educação das crianças para um mundo sustentável. Trad. Carmem Fischer. São Paulo: Cultrix, 2006.

CERBONE, D. R. Fenomenologia. (Tradução de Caesar Souza). 3. Ed. Petrópolis, RJ: Vozes, 2014.

CORRÊ A, M.P. Dicionário das Plantas úteis do Brasil e das Exóticas Cultivadas. Rio de Janeiro, Imprensa Nacional, 1984.

CRESWELL, John W. Projeto de pesquisa: métodos qualitativo, quantitativo e misto. [tradução Mágda Lopes; consultoria, supervisão e revisão técnica desta edição Dirceu da Silva]. $3^{\mathrm{a}}$ ed. Porto Alegre: Artmed, 2010.

CRUZ, G.L. Livro Verde das Plantas Medicinais e Industriais do Brasil. Belo Horizonte, G.L. Cruz, 1965.

DELIZOICOV, Demétrio; ANGOTTI, José A.; PERNAMBUCO, Marta Maria. Ensino de Ciências: fundamentos e métodos. São Paulo: Cortez, 2011.

FEYERABEND, P. K. Contra o Método. Lisboa: Relógio D’ Água, 1993.

GASPAR, L. Mercado Adolpho Lisboa,Manaus, AM. Pesquisa Online 2012. Fundação Joaquim Nabuco, Recife. Disponível em: http://basilio.fundaj.gov.br/pesquisaescolar/index.php?option=com_content\&id=906\%3Amer cado-adolpho-lisboa-manaus-am. Acesso em: 20 de outubro de 2017.

GONZAGA, A. M. Reflexões sobre o Ensino de Ciências. Curitiba: CRV, 2013.

KUNH, T. S. A estrutura das revoluções científicas. [tradução: Beatriz Vianna Boeira e Nelson Boeira]. 13, ed. São Paulo: Perspectiva, 2017.

LAMEIRA, O. A.; PINTO, J. E. B. P. Plantas medicinais: do cultivo, manipulação e uso à recomendação popular. Embrapa Amazônia Oriental. Belém, PA: 2008.

LEÃO,A. L. C.;SILVA, L. M. A.Fazendo educação ambiental. Recife: CPRH, 1995.

MERLEAU-PONTY, M. Fenomenologia da percepção(C. Moura, Trad.). São Paulo: Martins Fontes, 1994.

MORIN, E. Educar na era planetária: o pensamento complexo como método de aprendizagem no erro e na incerteza humana; trad. Sandra TrabuccoValenzuela. São Paulo: Cortez; Brasília, DR: UNESCO, 2003. 


\section{REVISTA REAMEC}

Revista da Rede Amazonitica de Edurecråo em Ciências e Matemática
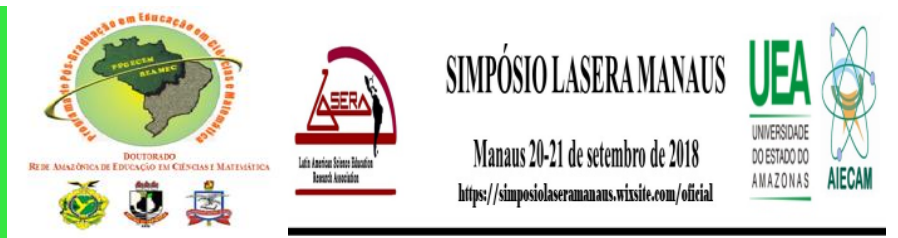

OlIVEIRA, A. X.; COELHO, M. F. B. Uso de Plantas Medicinais. Brasília: LK Editora, 2007.

OLIVEIRA, R. C. de. O trabalho do antropólogo: olhar, ouvir, escrever. In: O trabalho do antropólogo. Paralelo 15, São Paulo, Unesp, 2000.

PEREIRA, M. M.; SOUZA JÚNIOR, S. N., ALCÂNTARA, A. F. C.; PILÓ-VELOSO, D.; ALVES, R. B.; MACHADO, P. O.; AZEVEDO, A. O.; MOREIRA, F. H.; CASTRO, M. S. A.; RASLAN, D. S. Constituintes químicos e estudo biológico de Aspidospermanitidum (Apocynaceae). Revista Brasileira de Plantas Medicinais. São Paulo: Botucatu, 2006.

RIBEIRO, J.E.L.S. et al. Guia de identificação das plantas vasculares de uma floresta de terra-firme na Amazônia Central. Manaus: Midas Printing, 1999.

SILVA, J. R. da. Políticas públicas de turismo: análise do desempenho das instâncias de governança turística e seus reflexos no fomento do turismo cultural no município de Manaus/AM. Manaus: UFAM, 2015. 